\title{
Severe acute respiratory syndrome coronavirus 2 for physicians: Molecular characteristics and host immunity (Review)
}

\author{
JIN SHANG $^{1 *}$, LINGYAO DU ${ }^{1 *}$, NING HAN ${ }^{1}$, DUODUO LV ${ }^{1}$, JIAYI WANG ${ }^{2}$, \\ HAILING YANG ${ }^{3}$, LANG BAI ${ }^{1}$ and HONG TANG ${ }^{1}$ \\ ${ }^{1}$ Center of Infectious Diseases, West China Hospital of Sichuan University; ${ }^{2}$ West China School of Medicine, \\ Sichuan University, Chengdu, Sichuan 610041, P.R. China; ${ }^{3}$ Graduate Program in Cellular and Molecular Physiology, \\ Graduate School of Biomedical Sciences, Tufts University School of Medicine, Boston, MA 02111, USA
}

Received May 11, 2020; Accepted September 18, 2020

DOI: $10.3892 / \mathrm{mmr} .2021 .11901$

\begin{abstract}
Recently, severe acute respiratory syndrome (SARS) coronavirus (CoV) 2 (SARS-CoV-2)-causing CoV disease 2019 (COVID-19) emerged in China and has become a global pandemic. SARS-CoV-2 is a novel $\mathrm{CoV}$ originating from $\beta$-CoVs. Major distinctions in the gene sequences between SARS-CoV and SARS-CoV-2 include the spike gene, open reading frame (ORF) $3 \mathrm{~b}$ and ORF 8. SARS-CoV-2 infection is initiated when the virus interacts with angiotensin-converting enzyme 2 (ACE2) receptors on host cells. Through this mechanism, the virus infects the alveolar, esophageal epithelial, ileum, colon and other cells on which ACE2 is highly expressed, causing damage to target organs. To date, host innate immunity may be the only identified direct factor associated with viral replication. However, increased ACE2 expression may upregulate the viral load indirectly by increasing the baseline level of infectious virus particles. The peak viral load of SARS-CoV-2 is estimated to occur $\sim 10$ days following fever onset, causing patients in the acute stage to be the primary infection source. However, patients in the recovery stage or with occult infections can also be contagious. The host immune response in patients with COVID-19 remains to be elucidated. By studying other SARS and Middle East respiratory syndrome coronaviruses, it is hypothesized that patients with COVID-19 may lack sufficient antiviral T-cell responses, which consequently present with innate immune response disorders. This may to a certain degree explain why
\end{abstract}

Correspondence to: Professor Hong Tang or Professor Lang Bai, Center of Infectious Diseases, West China Hospital of Sichuan University, 37 Guoxue Alley, Chengdu, Sichuan 610041, P.R. China E-mail: htang6198@hotmail.com

E-mail: pangbailand@163.com

*Contributed equally

Key words: 2019 novel coronavirus, severe acute respiratory syndrome coronavirus, molecular characteristics, immune response, angiotensin-converting enzyme 2 this type of $\mathrm{CoV}$ triggers severe inflammatory responses and immune damage and its associated complications.

\section{Contents \\ 1. Introduction \\ 2. Literature review \\ 3. Etiology \\ 4. Viral distribution and dynamics \\ 5. Immune response and pathogenesis \\ 6. Conclusions}

\section{Introduction}

During the Middle of December 2019, a virus-induced pneumonia emerged in Wuhan, China, which ultimately resulted in the current global pandemic (1). In the first few days of its emergence, this disease was simply identified as a virus-related respiratory disease. However, the original pathogen remained unclear (2). In early January 2020, the specific virus was isolated and later identified as a novel coronavirus by sequencing (3). The virus was first officially named the 2019 novel coronavirus (nCoV) by the World Health Organization (WHO) and subsequently termed 'severe acute respiratory syndrome CoV 2 (SARS-CoV-2)' by The International Committee on Nomenclature of Viruses. The virus is highly infectious and has infected $>10,000$ individuals in China and other countries. Since the virus presented the potential to result in a pandemic, the WHO declared a public health emergency of international concern on this epidemic on the 31st January 2020. The virus primarily infects the respiratory tract, resulting in pneumonia, acute respiratory distress syndrome (ARDS) and other fatal complications, including acute kidney injury, coagulation dysfunction and shock, according to a published report (4). Collectively, all the associated diseases caused by SARS-CoV-2 are termed Coronavirus Disease of 2019 (COVID-19). Therefore, knowledge on the molecular characteristics and host immunity in reaction to the virus would aid physicians to further understand the disease, manage patients and implement the occupational precautions. However, since it 
is a novel virus, the detailed underlying mechanisms are yet to be fully elucidated. As an accurate profile of the virus is urgently required, the present article screened the available literature on SARS-CoV-2 and other members of the coronavirus family to perform a literature review.

\section{Literature review}

The databases of Pubmed (date of access, 20/08/2020; https://pubmed.ncbi.nlm.nih.gov/), Web of Science (date of access, 20/08/2020; https://apps.webofknowledge.com/), Library, Information Science \& Technology Abstracts (date of access, 20/08/2020; https://connect.ebsco.com/) and Library of Congress (date of access, 20/08/2020; https://www.loc.gov/) were screened with a date range from 2003 to 2020, using primary key words, including 'coronavirus', 'human coronavirus', 'coronavirus pneumonia', '2019 novel coronavirus', '2019-nCoV', 'severe acute respiratory syndrome coronavirus 2', 'SARS-CoV-2', 'Coronavirus Disease 2019' or 'COVID-19', and secondary key words, including 'molecular characteristics', 'biological characteristics', 'immune response', 'immunity' or 'pathogenesis'. Articles with information on epidemiology, etiology, pathophysiology, clinical characteristics, therapeutic and preventive strategies of COVID-19 were preferred, along with articles concerning severe acute respiratory syndrome (SARS), Middle East respiratory syndrome (MERS) or other coronavirus infections in high-quality journals with high impact factors, high index or with reputations in infectious diseases. The selected articles were categorized based on the abstract and those deemed to be pertinent were carefully read by $\geq$ two authors: LD, JS and/or JW. The major conclusions of the selected articles were then summarized in the current review. Through properly summarized information and scientific speculation, the present review aimed to provide insights regarding the novel coronavirus for clinical physicians.

\section{Etiology}

Coronavirus. Coronaviruses are RNA viruses that are distributed broadly worldwide. This family of viruses has a large genetic diversity and high prevalence of genome recombination (5). In taxology, these viruses belong to the Nidovirales (Order), Coronaviridae (Family), Coronavirus (Genus) and Orthocoronavirus (Sub-genus), which consist of four species $(\alpha, \beta, \gamma$ and $\delta$ ) (6). Coronaviruses can only infect vertebrates. The viral particles are spherically and irregularly shaped with a diameter of 60-220 nm. Under an electron microscope, the core particle is wrapped in an envelope with 'spines', giving it a crown-like appearance, and was therefore termed 'coronavirus'. Within the envelope, there are three glycoproteins: i) The spike protein (S protein), which functions as the main antigen and contains receptor-binding sites to mediate cytolytic actions; ii) the envelope protein (E protein), which is a small glycoprotein forming the envelope; and iii) the membrane protein (M protein), which is a transmembrane transportation protein with functions in nutrition intake, maturation of the viral envelope, packaging and budding of progeny viruses (5). The spines observed using electron microscopy are comprised of S proteins. As $\mathrm{S}$ protein works as the main epitope for host immune recognition, the spines on different coronaviruses exhibit significant heterogeneity (7).
Over the previous decades, six coronavirus species that are able to cause human diseases have been identified: 229E, OC43, NL63, HKU1, SARS-CoV and MERS-CoV (6). Outbreaks of SARS-CoV and MERS-CoV occurred in 2003 and 2012, respectively, resulting in severe respiratory syndrome and fatal illness $(8,9)$.

Novel coronavirus. SARS-CoV-2. The first reported clinical case of the novel virus can be traced back to the middle of December 2019 (1). Following this, the novel coronavirus was isolated and an outbreak followed in January 2020 (10).

SARS-CoV-2 belongs to the $\beta$-coronavirus $(\beta-\mathrm{CoV})$ subfamily. Similar to its family members, the diameter of SARS-CoV-2 is $60-140 \mathrm{~nm}$. The viral particles exhibit distinctive spikes, which are generally spherical and exhibit certain pleomorphisms (1). According to the RNA sequences of SARS-CoV-2 isolated from three patients with unknown pneumonia in the early stage of the outbreak, the SARS-CoV-2 genome has a typical $\beta$-coronavirus composition, with $>85 \%$ nucleotide sequence similarity to that of the bat SARS-like CoV (bat-SL-CoVZC45; MG772933.1) genome (3). A few days later, the sequence was confirmed further in another study by sequencing the results from nine inpatients, which demonstrated that SARS-CoV-2 is closely related to bat-SL-CoVZC21 (3). Although there is a potential evolutionary link between SARS-CoV and SARS-CoV-2, SARS-CoV-2 is in a different clade from SARS-CoV and MERS-CoV. Genome sequencing revealed that SARS-CoV-2 only shares $79.0 \%$ nucleotide homology with SARS-CoV and 51.8\% with MERS-CoV $(11,12)$. In addition, the conserved replicase domain (ORF 1ab) of SARS-CoV-2 is $<90 \%$ homologous to other $\beta$-CoVs (3). Therefore, the SARS-CoV-2 is a novel CoV originating from $\beta-\mathrm{CoVs}$ and may have distinct pathogenic features.

Genomic structure of SARS-CoV-2. SARS-CoV-2 and SARS-CoV share a similar genomic structure with other members of the $\beta-\mathrm{CoV}$ family (3). $\beta$-CoVs have a typical genome structure with a 5'-untranslated region (UTR), ORF 1ab, S gene, E gene, M gene, nucleocapsid gene (N gene), 3'-UTR and several unidentified nonstructural ORFs (Fig. 1) (13). ORF 1 ab in particular is also known as the pol gene and comprises $\sim 60 \%$ of the genome, which encodes RNA-dependent RNA polymerase (RdRp), proteinase and other undefined proteins. Genome sequencing results revealed major distinctions between SARS-CoV and SARS-CoV-2 in the $\mathrm{S}$ gene, ORF $3 \mathrm{~b}$ and ORF 8 (14).

The $S$ protein functions as an epitope of host immune recognition (15). During the SARS epidemic, development of SARS vaccines and several preventive strategies were generally focused on the $S$ protein (16). High variations in the $S$ protein influences viral antigenicity and caused challenges for vaccine development to date. However, there is a conserved region located within the encoding gene of the $\mathrm{S}$ protein. The gene sequence of the $\mathrm{S} 2$ subunit of the S glycoprotein is highly conserved and shares $99 \%$ homology with other SARS-like CoVs and SARS-CoV, which may serve as a potential therapeutic target $(3,11)$. Notably, the receptor-binding domain (RBD) of S1 subunits, which is responsible for interaction with host receptors, is similar (73-76\% in homology) between SARS-CoV-2 and SARS-CoV $(17,18)$. However, the RBD is 


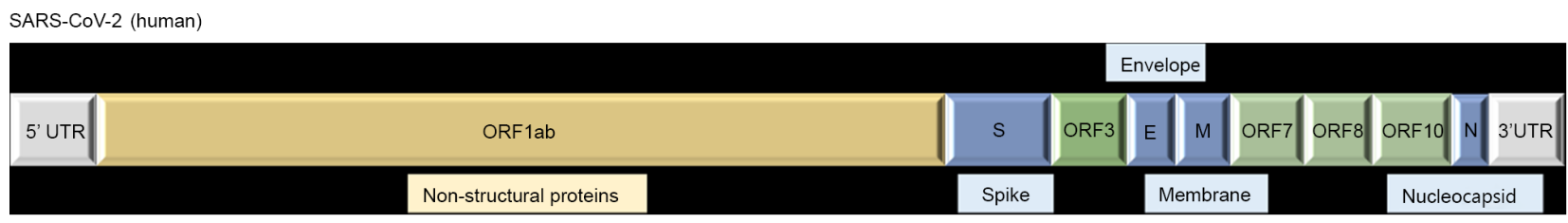

Figure 1. Schematic of the SARS-CoV-2 RNA genome. SARS, severe acute respiratory syndrome; CoV, coronavirus; UTR, untranslated region; ORF, open reading frame; S, spike; E, envelope; $M$, membrane; $N$, nucleocapsid.

different between SARS-CoV-2 and bat SARSr-nCoV. The $S$ protein was reported to interact with the host receptor and angiotensin-converting enzyme 2 (ACE2), and regulate cross-species and human-to-human transmission (19). According to sequence analysis, SARS-CoV-2 also binds with greater affinity to ACE2 compared with SARS-CoV (17). This may partly explain why SARS-CoV-2 exhibits cross-species transmission similar to SARS-nCoV, whilst bat SARSr-nCoV does not.

A novel short putative protein within ORF $3 \mathrm{~b}$ has been detected in SARS-CoV-2 (20). A deletion in ORF 3b was found to inhibit viral replication by promoting type I interferon (IFN) signaling during SARS-CoV pathogenesis $(21,22)$. The function of this shortened protein within ORF $3 b$ of SARS-CoV-2 warrants further investigation. Furthermore, ORF 8 from SARS-CoV-2 is highly variable from that of SARS-CoV, encoding a novel protein that is distinct from the conserved ORF 8-derived protein $(20,23)$. Theoretically, it may encode serine/threonine kinases with unknown function (24).

Although SARS-CoV-2 has a distinct genome sequence, detection of SARS-CoV-2 is not challenging. Reverse transcription-quantitative PCR is effective in identifying SARS-CoV-2 infection $(25,26)$. Furthermore, the E and RdRp genes are notably different between SARS-CoV-2 and other types of coronaviruses, such that the PCR detection of the E and RdRp genes is also highly sensitive (27). Therefore, E and RdRp genes may also serve to be potential therapeutic targets and promising vaccine candidates, similar to the $\mathrm{S}$ gene. The E gene is involved in the viral cycle of CoVs, whilst the RdRp protein is essential for the progression of viral replication and transcription (27). The highly conserved RdRp gene sequence suggests that potent agents developed for SARS-CoV RdRp may also exhibit equal potency and efficacy for SARS-CoV-2 RdRp. For instance, aurintricarboxylic acid, an anionic polymer that has been proven to bind to viral proteins, including RdRp of SARS-CoV and gp120 of human immunodeficiency virus, prevents SARS-CoV replication by targeting RdRp (28). However, the efficacy of targeting the RdRp of SARS-CoV-2 requires further investigation (28).

Infectivity of SARS-CoV-2. SARS-CoV, MERS-CoV and SARS-CoV-2 are the three most notable coronaviruses known to infect humans $(2,29)$. Although they all primarily infect the respiratory tract, clinical differences exist in their transmissibility, incubation period and severity of symptoms (30). Among them, the infectious stages serve a major role in the magnitude of clinical and societal consequences (30). A recent review reported that SARS-CoV-2 had comparable or slightly higher transmissibility (average R0, 2.5) compared with SARS-CoV (average R0, 2.4), with the highest estimate of SARS-CoV-2 R0 being >3.5 compared with 2.5 for SARS-CoV (31). Moreover, the incubation time appears to be longer during illness from SARS-CoV-2 (4-12 days) compared with SARS-CoV (2-7 days). The most notable difference is that the interval between symptom onset and maximum infectiousness for SARS-CoV-2 is 0 days (5-7 days in SARS-CoV), suggesting that the illness can be readily transmitted by patients who are not exhibiting symptoms (31). Therefore, unsurprisingly, SARS-CoV-2 has a higher R0 due to infectiousness in asymptomatic patients and a longer incubation period. As for MERS-CoV, R0 was reported to be 0.9 , consistent with the fact that this illness has only resulted in regional outbreaks to date (31). The earliest case of MERS was identified in a hospital-associated cluster, where the disease appeared to be infrequent outside health care settings, though several household clusters have been documented (32). Symptomatic MERS usually presents following an incubation period of 2-14 days (33). Once MERS is suspected, respiratory specimens obtained within 7 days of symptom onset typically have the best diagnostic sensitivity, indicating that the peak in viral load and infectiveness may present during the incubation time of MERS (34). Although several regional studies from South Korea and Middle Eastern areas between 2012 and 2017 have reported different incubation periods (6-7.8 and 4.5-5.5 days, respectively), no difference in incubation times were found (35). Furthermore, the range of incubation time for MERS-CoV (2-14 days) is relatively longer compared with that of SARS-CoV-2 (4-12 days) (36).

\section{Viral distribution and dynamics}

Target cells and distribution of SARS-CoV-2 in the host. Coronaviruses primarily infect the respiratory and digestive systems (37). Reported symptoms range from mild and self-limiting illnesses, including common colds, fever or diarrhea, to severe symptoms, including severe pneumonia with renal damage or cardiac involvement and even death $(37,38)$. The global mortality rates of SARS-CoV and MERS-CoV were reported to be 9 and 26.6-59.4\%, respectively $(39,40)$.

The initial step of viral infection is entry into host cells (5). A number of studies have demonstrated that the sequences of SARS-CoV-2 and SARS-CoV appear to be homologous $(41,42)$, with similar $S$ proteins that have strong binding affinities to the human cell receptor ACE2 (41). Therefore, ACE2-expressing cells, including pulmonary type II alveolar (AT2) cells, may serve as the primary target cells that are susceptible to SARS-CoV-2 infection (11). Distribution of ACE2 receptor expression is crucial in identifying target cells to provide evidence for the distribution of SARS-CoV-2 infection throughout the body. 
A previous article indicated that ACE2 was highly expressed in alveolar, esophageal epithelial, ileum and colon cells (43). Following this study, researchers used the latest single-cell RNA sequencing data to analyze the expression of ACE2 in the respiratory, cardiovascular, digestive and urinary systems. The results demonstrated that cells in the heart, esophagus, kidneys, bladder and ileum exhibited similar or higher expression of ACE2 compared with that in AT2 cells, suggesting that these organs may be at risk of SARS-CoV-2 infection (44).

The lungs are the primary target of SARS-CoV-2 and other SARS-CoV-like coronaviruses, and they exhibit more severe clinical symptoms compared with other organs $(4,45)$. Additionally, the lower respiratory system suffers more prominent damage than the upper system, where certain patients with severe infection rapidly develop ARDS $(45,46)$. On January 24 2020 , an article concerning patients with early SARS-CoV-2 first reported that the virus was detected in the bronchoalveolar lavage fluid of three patients (1). A number of studies published in succession indicated that patients with SARS-CoV-2 infection presented with pneumonia and various clinical symptoms, including fever, cough and fatigue $(45,47,48)$. However, symptoms of the upper respiratory system, such as nasal congestion and rhinorrhea, were not obvious. Therefore, recommended specimens of the upper respiratory system for diagnostic tests include nasopharyngeal and oropharyngeal swabs (49). According to a study in Hong Kong, the initial saliva samples of 11/12 patients tested positive following admission (50). In six patients who were continuously monitored, the viral load in the saliva exhibited a declining trend (50). Furthermore, the saliva culture of three patients in this study indicated the presence of the live virus (50).

Aside from pulmonary manifestations, a previous study reported that the levels of liver enzymes in 43 patients were higher compared with those in the normal range, where one patient presented with liver function impairment (48). Moreover, another previous study indicated that the virus may infect cholangiocytes, which also express ACE2, but not hepatocytes, which do not express ACE2 $(51,52)$. It is possible that the abnormal liver function was the result of biliary cell dysfunction or other causes, such as medication, instead of hepatocyte damage (52). Therefore, patients with SARS-CoV-2 should receive specialized tests and medical care to ensure that their liver function recovers during hospitalization.

Patients with coronavirus infection may also present with diarrhea and gastrointestinal-associated symptoms (53). In patients with MERS-CoV, sub-genomic virus RNA, which was indicative of viral replication, was observed in stool specimens (53). Additionally, certain patients with COVID-19 were reported to present with atypical symptoms, including diarrhea, similar to those with SARS-CoV and MERS-CoV infections (48). Concurrently, recent epidemiologic studies have indicated that the nucleic acid test in stool samples for SARS-CoV-2 could return positive $(48,54)$. However, it is unclear whether SARS-CoV-2, an envelope virus, can remain infectious in the presence of bile and proteolytic enzymes in the digestive system.

Although certain patients presented with heart and kidney ailments, there were insufficient studies that have confirmed the presence of the virus in these organs. A previous study indicated that SARS-CoV-2 may bind the ACE2 receptors of tubular cells, causing cytotoxicity and abnormal renal function $(55,56)$. Additionally, the researchers reported high expression of ACE2 in testicular, spermatogenic tube and interstitial cells (56).

The first pathological report on patients who succumbed to COVID-19 only obtained specimens of the lungs, liver and heart by puncture, rather than performing a complete autopsy $(57,58)$. Therefore, data that could be used to support the hypothesis that SARS-CoV-2 directly damages the heart and liver was not obtained (57). Further pathological evidence is urgently required to study COVID-19 in this regard.

Viral load at different clinical stages. Since the viral load is proportional to the transmission capacity of the virus, clarifying the viral dynamic patterns of SARS-CoV-2 is crucial (59). During SARS-CoV infection, viral concentration in the respiratory tract is the highest during the febrile period (60). As SARS-CoV-2 is a relative of SARS-CoV, it can be hypothesized that respiratory secretions are highly contagious during the acute febrile phase of SARS-CoV-2 infection. Previous publications on SARS-CoV reported that certain patients presented with fever, myalgia and other symptoms, which were resolved within a few days. During this phase, the viral load increased continuously, peaking on day 10. As the disease progressed, IgG seroconversion occurred and the viral load began to decrease between days 10-15 (59). Lung damage during this phase may be caused by immunopathological damage as a result of an hyperactive host response (59). Other studies have demonstrated a slightly different peak in viral load on days 10-15 following fever onset (61-63). However, patients in these studies were treated with hydrocortisone, which may have resulted in a delayed peaking of viral load (61-63). Furthermore, Lo et al (64) previously reported that SARS-CoV was detected in plasma on days 3 and 4 following fever onset, where peak concentration was identified during the first week, followed by a rapid decline in the second week. This indicated that the SARS-CoV-2 may reach peak viral load $\sim 10$ days following fever onset like its relatives.

Apart from the febrile period, the virus replicates from initial infection up until elimination (59). Early in the latent period, the virus endows patient infectivity (65). Furthermore, the presence of the virus can be detected during the recovery phase, indicating that recovering patients may also be contagious (33). Moreover, according to several case reports, individuals with occult infections of SARS-CoV-2 can also be contagious, although this has not been previously reported in patients with SARS-CoV $(43,44)$. Two scenarios may occur in patients during the asymptomatic phase: Either the patient is in the early stage of disease or the patient is an asymptomatic carrier. In the former scenario, previous studies have reported a relatively high viral load of coronavirus in the epithelial cells of the upper respiratory tract in the first few days following infection compared with the latter days $(64,66)$. As death of these epithelial cells occurs in the early stage of disease, the virus released by those cells primarily account for the infectiousness (64). In the latter scenario, since ACE2-induced angiotensin II degradation is essential for the pathogenesis of coronaviruses (67), disease severity depends on the maturity and binding capacity of ACE2. Therefore, asymptomatic 
carriers may exhibit lower expression of ACE2, causing an impaired binding capacity with SARS-CoV-2 in certain patients. Notably, during the outbreak of SARS in 2003, reports of asymptomatic patients were rare (68). However, asymptomatic SARS-CoV carriers were reported in a retrospective study in Guangzhou (China), following a community outbreak in 2004 (69). Similarly, in the early phase of the MERS outbreak, asymptomatic carriers were also rare (70). Nonetheless, a recent review in 2019 reported an increased asymptomatic rate of $\leq 28.6 \%$ among all MERS-CoV infections (71). It is possible that the increased rate of asymptomatic carriers was associated with advanced surveillance and completion of more diagnostic tests. When COVID-19 emerged in China, healthcare workers were prepared due to experience with surveillance and had access to abundant facilities for testing. Consequently, asymptomatic carriers were identified rapidly following the outbreak in Wuhan (China). Additionally, cases of transmission were confirmed. Viral load served an important role in viral transmission (72,73). The viral load in an asymptomatic carrier of SARS-COV-2 was similar to that in symptomatic patients, suggesting that the transmission capacity of asymptomatic carriers was equal to that in clinically diagnosed patients (73).

These aforementioned publications indicate that, in addition to patients in the acute stage, those at different clinical stages or those with asymptomatic infection also require proper evaluation of their contagious capacities and potentially isolation for disease management.

Factors influencing viral replication of SARS-CoV-2. The natural course of viral infection is intricate and variable, making it challenging to identify the influential factors underlying viral replication. Currently, the full-length genome sequencing results of different virus samples obtained from patients with COVID-19 were almost identical with a few site mutations (74), indicating that this virus has yet to undergo significant mutations.

In the host, the innate immune response determines the level of the coronavirus replication (50). Previously published studies reported that patients with cancer may have an increased risk of contracting SARS-COV-2 and present with associated poor prognosis due to immunosuppression $(37,75,76)$. Additionally, age was revealed to be an independent risk factor for incidence of severe events, including intensive care unit (ICU) admission, invasive ventilation and death in patients with tumors $(75,77)$. Therefore, factors associated with impaired immunity, including old age and the presence of tumors, may downregulate the innate immune response of the host and accelerate viral replication, resulting in disease deterioration (76,77).

To date, host innate immunity may be the only direct factor identified to be associated with viral replication (78). However, increased ACE2 expression may also upregulate the viral load indirectly by increasing the baseline level of infectious viruses (79). A study previously analyzed large-scale datasets of four lung tissues from patients with lung cancer to investigate differences in ACE2 gene expression by ethnicity, age, sex and smoking status. The results demonstrated that the expression of ACE2 was higher in individuals who smoked compared to non-smoking controls (80). Therefore, smoking may upregulate the expression of cellular receptors, indirectly increasing viral replication. Nonetheless, direct evidence of smoking being associated with viral replication remains to be elucidated.

\section{Immune response and pathogenesis}

Innate immune response to coronavirus infection. As mentioned previously, the replication of human coronaviruses (hCoVs) is regulated by various host factors and immune interaction (81). The first interaction occurs through innate immunity (82). Although antiviral T-cells and antibodies are essential for virus clearance, the effectiveness of the innate immune response serves a decisive role in viral replication and sequential clearance from the host (81). Innate immunity is initiated by pattern recognition receptors (PRRs), which recognize pathogen-associated molecular patterns or virus-associated molecules $(83,84)$. The virus activates PRRs on cells and triggers the production and release of type I and III IFNs or other proinflammatory mediators. These mediators then initiate the sequential immune response or extensive immune damage $(13,85)$. During SARS-CoV infection, this specialized type I IFN response pattern is essential for controlling potentially fatal viral infections (86). Researchers have previously demonstrated that plasma cell-like dendritic cells inhibited SARS-CoV replication through the immediate production of type I IFN, via the toll-like receptor 7-mediated recognition of viruses (87). Considering the potential antiviral efficacy of type I IFN in eliminating coronaviruses, aerosol inhalation of IFN was recommended in China for patients with COVID-19, to inhibit viral replication in the respiratory tract (88).

Besides activation, hCoVs can also inhibit the innate immune response by shielding viral RNA from host cell sensors to inhibit IFN induction (89). MERS-CoV encodes several structural and nonstructural proteins to negate the innate antiviral immune response $(90,91)$. The structural proteins $\mathrm{M}$ and $\mathrm{N}$ and the auxiliary proteins derived from the ORF 3 and ORF 4 in MERS-CoV have been demonstrated to downregulate IFN signaling $(90,91)$. Therefore, conserved structural proteins $\mathrm{M}, \mathrm{N}$ and ORF 3 in SARS-CoV-2 may also downregulate endogenous IFN signaling via this mechanism, resulting in delayed or even failed clearance of the virus in certain patients.

Furthermore, coronaviruses induce the production of chemokines and cytokines other than IFN in the innate immune system. SARS-CoV infection can result in the moderate upregulation of inflammatory cytokine such as tumor necrosis factor (TNF) and interleukin (IL)-6 and significant upregulation of the chemokine ligand (CCL) 3, CCL5, CCL2 and chemokine (C-X-C motif) ligand (CXCL) 10 in macrophages and dendritic cells $(92,93)$. When this response is overactivated, inflammatory damage occurs. For example, higher serum levels of proinflammatory cytokines (IFN- $\gamma$, IL-1, IL-6, IL-12 and transforming growth factor $\beta$ ) and chemokines (CCL2, CXCL10, CXCL9 and IL-8) were observed in patients with severe SARS-CoV infection, compared with those with milder symptoms $(94,95)$. During MERS-CoV infection, chemokines and proinflammatory cytokines, including CCL2, CCL3, CCL5, IL-2 and IL-8, were found to be elevated in monocyte-derived macrophages and dendritic 
cells, albeit in a delayed pattern compared with SARS-CoV infection (96-98). Consistently, serum proinflammatory cytokines (IL-6 and IFN- $\alpha$ ) and chemokines (IL-8, CXCL10 and CCL5) were found to be elevated in patients with severe MERS compared with those in patients with mild or moderate conditions $(99,100)$. By analyzing the plasma of patients with COVID-19 from Wuhan, a previous study observed that the baseline levels of IL-1B, IL-1RA, IL-7, IL-8, IL-9, IL-10, fibroblast growth factor, granulocyte-colony stimulating factor, granulocyte macrophage-colony stimulating factor, IFN $\gamma$, interferon $\gamma$-induced protein $10 \mathrm{kDa}$ (IP10), monocyte chemoattractant protein-1 (MCP-1), macrophage inflammatory protein (MIP) 1A, MIP1B, platelet-derived growth factor, $\mathrm{TNF} \alpha$ and vascular endothelial growth factor concentrations in serum were higher in both patients in ICU and non-ICU patients compared with those in healthy individuals (45). By contrast, serum levels of IL-5, IL-12p70, IL-15, eotaxin and CCL5 were similar between patients with COVID-19 and healthy adult individuals (45). Further comparison between patients in the ICU and non-ICU patients demonstrated higher serum levels of IL-2, IL-7, IL-10, G-CSF, IP10, MCP1, MIP1A and TNF $\alpha$ in patients in the ICU (45). These observations suggest that cytokine and chemokine dysregulation and/or overreaction caused by viral infection may serve an important role in the pathogenesis of coronavirus infection.

Adaptive immune response to coronavirus infection. Previous reports have demonstrated that the acute phase in patients with SARS-CoV infection is associated with leukopenia and severe lymphopenia in $>80 \%$ patients, involving a marked loss of 90-100 and 80-90\% in $\mathrm{CD}^{+}{ }^{+} \mathrm{T}$ and $\mathrm{CD} 8^{+} \mathrm{T}$-cells, respectively (101-103). Additionally, leukopenia and associated lymphopenia were observed in patients with MERS, but to a lesser degree compared with patients with SARS $(30,104)$. A previous clinical study reported that $14 \%$ patients with MERS had leukopenia, whilst $34 \%$ presented with lymphopenia (104). Furthermore, early in the epidemic, leukopenia and associated lymphopenia were included into the diagnostic criteria of COVID-19 (105). A study of 41 patients with COVID-19 revealed that $63 \%$ patients had lymphopenia (45). Another previous analysis of 1,099 patients with COVID-19 reported lymphopenia in $82.1 \%$ of the samples obtained (4).

Two Chinese studies reported impaired $\mathrm{CD}^{+}$and $\mathrm{CD} 8^{+}$ T-cell activation in patients with SARS-CoV $(106,107)$. The suppressed activation of $\mathrm{T}$ lymphocytes indicated reduced cellular immunity in patients with SARS-CoV, particularly those with severe conditions (107). Due to the lack of optimal animal models of SARS, a number of laboratories developed an adaptive strain of SARS-CoV, termed MA15 and established an in vivo mouse model (108-110). The results demonstrated that following SARS-CoV-MA15 infection in elderly mice (age, 6 months), proinflammatory cytokines (TNF- $\alpha$, IL-6, IL-8, IP-10 and MCP-1) and chemokines (CXCL1, CXCL2, CCL3 and CCL5) were upregulated, but the levels of virus-specific $\mathrm{CD}^{+} \mathrm{T}$-cells were significantly reduced compared to young mice (age, 6 weeks). Furthermore, in older mice (age, 12 and 22 months), the levels of cytokines and virus-specific $\mathrm{CD}^{+}$ T-cells were not significantly different compared with the elderly mice (age, 6 months) $(108,111)$. Although decreases in the levels and activation of T-cells were closely associated the severity of SARS in the acute phase $(102,112)$, the effect of T-cells in patients with MERS remains unclear. Considering T-cells are essential for the control of the innate immune response, lack of an effective antiviral T-cell response may result in disorders of the innate immune response and pathological deterioration (113). Additionally, reported data indicated that older patients ( $\geq 65$ years old) with COVID-19 were more commonly admitted into the ICU (4).

Several studies have previously identified virus-specific memory $\mathrm{CD}^{+}$and $\mathrm{CD} 8^{+} \mathrm{T}$-cells in patients who recovered from SARS (114-116). Virus-specific memory CD8 ${ }^{+} \mathrm{T}$-cells targeting major histocompatibility complex class IA*02:01 restricting the epitopes on the S protein (SSp-1, S978 and S1202) were observed $>1$ year post-infection (117). These cells produced high levels of antiviral cytokines (IFN- $\gamma$ and TNF- $\alpha$ ) and cytotoxic molecules (perforin and granzyme B) following peptide stimulation in vitro (117). However, whether virus-specific memory T-cells are present in patients who recovered from COVID-19 remains controversial. This information is important for estimating the impact of future COVID-19 epidemics.

Immune damage caused by coronavirus infection. A recent meta-analysis compiled $>600$ studies to report a full clinical profile of COVID-19 (118). Among these patients, fever was the leading symptom [88.7\%; 95\% confidence interval (CI), $84.5-92.9 \%]$, followed by cough $(57.6 \%$; $95 \%$ CI, $40.8-74.4 \%)$ and dyspnea $(45.6 \%$; $95 \%$ CI, 10.9-80.4\%). In hospitalized patients, 32.8\% presented with ARDS (95\% CI, 13.7-51.8), $6.2 \%$ with shock (95\% CI, 3.1-9.3) and $13.9 \%$ with fatal outcomes (95\% CI, 6.2-21.5) (118).

In addition to virological tests, CT scans served vital roles for early detection and disease evaluation $(119,120)$. Peripherally distributed multifocal ground-glass opacities with patchy consolidations and/or posterior or lower lobe involvement predilection were the typical findings in lungs of patients with COVID-19, which warrant further evaluation (119). In the majority of cases, pulmonary architecture was compromised by the host immune response rather than $\mathrm{hCoV}$ replication (85). This is consistent with the fact that the immune response to respiratory viral infection, instead of direct injury from the virus, accounted for the pathological damage of cells in the respiratory system (85). Furthermore, an increase in neutrophils and monocyte numbers in the peripheral blood was reported to correlate with a reduction in $\mathrm{CD} 4^{+}$and $\mathrm{CD} 8^{+} \mathrm{T}$ cells in patients with severe SARS $(103,121)$. Histological evaluation of pulmonary samples from patients who succumbed to SARS revealed extensive infiltration of neutrophils and macrophages in the lung interstitial and alveolar cells $(122,123)$. Similarly, in patients with MERS, the severity of lung lesions was associated with extensive infiltration of neutrophils and macrophages in the lungs and peripheral blood (124). Additionally, inflammatory mediators serve a key role in the pathogenesis of ARDS (125). Several proinflammatory cytokines (IL-6, IL-8, IL-1 $\beta$ and GM-CSF) and chemokines (CCL2, CCL5, IP10 and CCL3) contribute to the incidence of ARDS, ultimately making ARDS the leading cause of death in patients with SARS or MERS (126-128).

Previous histological reports of patients who succumbed to COVID-19 revealed extensive infiltration of immune cells, 
including $\mathrm{CD}^{+}$helper T lymphocytes and $\mathrm{CD} 163^{+} \mathrm{M} 2$ macrophages $(129,130)$. In accordance with other previous reports concerning coronavirus infection, it can be hypothesized that the pathogenesis induced by the novel coronavirus is characterized by the continuously hyperactive innate immune response, induced by the delayed development of the adaptive immune response and prolonged virus clearance (131). Rapid virus replication and excessive pro-inflammatory cytokine/chemokine production then induce infiltration of inflammatory cells, resulting in airway and alveolar epithelial cell apoptosis (132). Moreover, the strong inflammatory response further reduces T-cell response by TNF-mediated T-cell apoptosis, aggravating tissue damage (133).

Immune damage results in thromboembolism in the lungs, heart and brain $(134,135)$. Microorganisms and their components activate the expression of multiple cytokines after binding to the pathogenic PPRs on immune cells (136). Host proinflammatory cytokines exhibit pleiotropic effects on the activation of coagulation (135). In patients with COVID-19, abnormal coagulation test results were observed in the early stages of disease though clinical bleeding did not occur (137). According to the present data, the SARS-CoV-2 virus did not present with an intrinsic procoagulant effect (137). Therefore, development of coagulopathy was likely a result of the profound inflammatory response. In the 99 patients first reported in Wuhan, $>1 / 3$ presented with abnormal coagulation parameters (48).

Activation of coagulation and thrombin generation results from the interaction between pathogens and host innate immunity (138). Thromboinflammation or immunothrombosis refers to the humoral and cellular pathways of signaling amplification (138). Invasive pathogen-associated components activate platelets, mast cells and factor XII in the contact pathway and serve further downstream roles (135). Circulating serine protease inhibitors, including antithrombin, are largely decreased during severe inflammatory responses (139). This may explain why the representative coagulopathy indicator, D-dimer, is associated with the severity of inflammatory parameters, such as IL-6, in patients with COVID-19 in the ICU (45).

Besides thromboinflammation, endotheliopathy also contributes to coagulation disorders in patients with COVID-19 (140). ACE2 on endothelial cells mediate viral adhesion and invasion (141). Sequential viral replication induces the infiltration of inflammatory cells and apoptosis of endothelial cells, leading to microvascular prothrombotic effects (141). Along with microcirculatory clot formation, microvascular endothelial injury was reported to facilitate thrombotic microangiopathy, including cerebrovascular complications or myocardial ischemia (137).

\section{Conclusions}

In conclusion, the current review compiled available data concerning COVID-19, which were then compared with SARS and MERS to profile the molecular characteristics of SARS-CoV-2 and the immune response against the virus. As a novel $\mathrm{CoV}$ originating from $\beta-\mathrm{CoVs}$, SARS-CoV-2 infects alveolar cells and other cells in which ACE2 is highly expressed, causing damage to target organs. Host immunity is crucial for viral replication and sequential pathogenesis. However, the comprehensive underlying mechanisms are yet to be fully elucidated. Based on the current data, it can be hypothesized that patients with SARS-CoV-2 infection may have insufficient antiviral T-cell responses, resulting in disorders of the innate immune response. To a certain degree, this may explain why this type of $\mathrm{CoV}$ triggers excessive inflammatory responses and immune damage due to COVID-19 and its associated complications.

\section{Acknowledgements}

Not applicable.

\section{Funding}

The current study was supported by Special Funds for Prevention and Control of COVID-19 of Sichuan University (grant no. 2020scunCoVyingji10004) and the Scientific and Technological Project for Prevention and Control of COVID-19 of West China Hospital of Sichuan University (grant no. HX-2019-nCoV-010).

\section{Availability of data and materials}

Not applicable.

\section{Authors' contributions}

HT and LB conceptualized and designed the current work. LD, JS, NH, DL and JW researched and evaluated the literature obtained from the database. LD and JS drafted the manuscript. LD, LB, HT and HY revised the manuscript. All authors read and approved the final manuscript.

\section{Ethics approval and consent to participate}

Not applicable.

\section{Patient consent for publication}

Not applicable.

\section{Competing interests}

The authors declare that they have no competing interests.

\section{References}

1. Zhu N, Zhang D, Wang W, Li X, Yang B, Song J, Zhao X, Huang B, Shi W, Lu R, et al: A novel coronavirus from patients with pneumonia in China, 2019. N Engl J Med 382: 727-733, 2020.

2. Andersen KG, Rambaut A, Lipkin WI, Holmes EC and Garry RF: The proximal origin of SARS-CoV-2. Nat Med 26: 450-452, 2020

3. Lu R, Zhao X, Li J, Niu P, Yang B, Wu H, Wang W, Song H, Huang B, Zhu N, et al: Genomic characterisation and epidemiology of 2019 novel coronavirus: Implications for virus origins and receptor binding. Lancet 395: 565-574, 2020.

4. Guan WJ, Ni ZY, Hu Y, Liang WH, Ou CQ, He JX, Liu L, Shan H, Lei CL, Hui DSC, et al: Clinical characteristics of coronavirus disease 2019 in ChinaN Engl J Med 382: 1708-1720, 2020.

5. Belouzard S, Millet JK, Licitra BN and Whittaker GR: Mechanisms of coronavirus cell entry mediated by the viral spike protein. Viruses 4: 1011-1033, 2012. 
6. Cui J, Li F and Shi ZL: Origin and evolution of pathogenic coronaviruses. Nat Rev Microbiol 17: 181-192, 2019.

7. Kahn JS and McIntosh K: History and recent advances in coronavirus discovery. Pediatr Infect Dis J 24 (Suppl 11): S223-S227, 2005.

8. de Wit E, van Doremalen N, Falzarano D and Munster VJ: SARS and MERS: Recent insights into emerging coronaviruses. Nat Rev Microbiol 14: 523-534, 2016.

9. Yin Y and Wunderink RG: MERS, SARS and other coronaviruses as causes of pneumonia. Respirology 23: 130-137, 2018.

10. Tan WJ, Zhao X, Ma XJ, Wang WL, Niu PH, Xu W, Gao GF and Wu GH: A novel coronavirus genome identified in a cluster of pneumonia cases-Wuhan, China 2019-2020. China CDC Weekly 2: 61-62, 2020.

11. Zhou P, Yang XL, Wang XG, Hu B, Zhang L, Zhang W, Si HR, Zhu Y, Li B, Huang CL, et al: A pneumonia outbreak associated with a new coronavirus of probable bat origin. Nature 579: 270-273, 2020

12. Gralinski LE and Menachery VD: Return of the coronavirus: 2019-nCoV. Viruses 12: 135, 2020.

13. Perlman S and Netland J: Coronaviruses post-SARS: Update on replication and pathogenesis. Nat Rev Microbiol 7: 439-450, 2009

14. Chan JF, Kok KH, Zhu Z, Chu H, To KK, Yuan S and Yuen KY: Genomic characterization of the 2019 novel human-pathogenic coronavirus isolated from a patient with atypical pneumonia after visiting Wuhan. Emerg Microbes Infect 9: 221-236, 2020.

15. Harrison SC: Viral membrane fusion. Nat Struct Mol Biol 15 690-698, 2008

16. Gao Q, Bao L, Mao H, Wang L, Xu K, Yang M, Li Y, Zhu L, Wang N, Lv Z, et al: Development of an inactivated vaccine candidate for SARS-CoV-2. Science 369: 77-81, 2020.

17. Wan Y, Shang J, Graham R, Baric RS and Li F: Receptor recognition by the novel coronavirus from wuhan: An analysis based on decade-long structural studies of SARS coronavirus. J Virol 94: e00127, 2020.

18. Ali A and Vijayan R: Dynamics of the ACE2-SARS-CoV-2/ SARS-CoV spike protein interface reveal unique mechanisms. Sci Rep 10: 14214, 2020.

19. Li F: Structure, function, and evolution of coronavirus spike proteins. Annu Rev Virol 3: 237-261, 2016.

20. Gordon DE, Jang GM, Bouhaddou M, Xu J, Obernier K White KM, O'Meara MJ, Rezelj VV, Guo JZ, Swaney DL, et al: A SARS-CoV-2 protein interaction map reveals targets for drug repurposing. Nature 583: 459-468, 2020.

21. Yount B, Roberts RS, Sims AC, Deming D, Frieman MB Sparks J, Denison MR, Davis N and Baric RS: Severe acute respiratory syndrome coronavirus group-specific open reading frames encode nonessential functions for replication in cell cultures and mice. J Virol 79: 14909-14922, 2005.

22. Kopecky-Bromberg SA, Martínez-Sobrido L, Frieman M, Baric RA and Palese P: Severe acute respiratory syndrome coronavirus open reading frame (ORF) 3b, ORF 6, and nucleocapsid proteins function as interferon antagonists. J Virol 81: 548-557, 2007.

23. Wu A, Peng Y, Huang B, Ding X, Wang X, Niu P, Meng J, Zhu Z, Zhang Z, Wang J, et al: Genome composition and divergence of the novel coronavirus (2019-nCoV) originating in China. Cell Host Microbe 27: 325-328, 2020.

24. Ceraolo C and Giorgi F: Genomic variance of the 2019-nCoV coronavirus. J Med Virol 92: 522-528, 2020.

25. Corman VM, Landt O, Kaiser M, Molenkamp R, Meijer A, Chu DK, Bleicker T, Brünink S, Schneider J, Schmidt ML, et al: Detection of 2019 novel coronavirus $(2019-\mathrm{nCoV})$ by real-time RT-PCR. Euro Surveill 25: 2000045, 2020.

26. Yu F, Du L, Ojcius DM, Pan C and Jiang S: Measures for diagnosing and treating infections by a novel coronavirus responsible for a pneumonia outbreak originating in Wuhan, China. Microbes Infect 22: 74-79, 2020

27. Schoeman D and Fielding B: Coronavirus envelope protein: Current knowledge. Virol J 16: 69, 2019.

28. Morse JS, Lalonde T, Xu S and Liu W: Learning from the past: Possible urgent prevention and treatment options for severe acute respiratory infections caused by $2019-\mathrm{nCoV}$. Chembiochem 21 : $730-738,2020$.

29. Rockx B, Kuiken T, Herfst S, Bestebroer T, Lamers MM, Oude Munnink BB, de Meulder D, van Amerongen G, van den Brand J, Okba NMA, et al: Comparative pathogenesis of COVID-19, MERS, and SARS in a nonhuman primate model. Science 368: 1012-1015, 2020
30. Petrosillo N, Viceconte G, Ergonul O, Ippolito G and Petersen E COVID-19, SARS and MERS: Are they closely related? Clin Microbiol Infect 26: 729-734, 2020.

31. Petersen E, Koopmans M, Go U, Hamer DH, Petrosillo N, Castelli F, Storgaard M, Al Khalili S and Simonsen L: Comparing SARS-CoV-2 with SARS-CoV and influenza pandemics. Lancet Infect Dis 20: e238-e244, 2020.

32. Memish ZA, Zumla AI, Al-Hakeem RF, Al-Rabeeah AA and Stephens GM: Family cluster of Middle East respiratory syndrome coronavirus infections. N Engl J Med 368: 2487-2494, 2013.

33. Arabi YM, Balkhy HH, Hayden FG, Bouchama A, Luke T, Baillie JK, Al-Omari A, Hajeer AH, Senga M, Denison MR, et al: Middle East respiratory syndrome. N Engl J Med 376: 584-594, 2017.

34. Memish ZA, Al-Tawfiq JA, Makhdoom HQ, Assiri A, Alhakeem RF, Albarrak A, Alsubaie S, Al-Rabeeah AA, Hajomar WH, Hussain R, et al: Respiratory tract samples, viral load, and genome fraction yield in patients with Middle East respiratory syndrome. J Infect Dis 210: 1590-1594, 2014.

35. Park J, Jung S, Kim A and Park JE: MERS transmission and risk factors: A systematic review. BMC Public Health 18: 574, 2018.

36. Fani M, Teimoori A and Ghafari S: Comparison of the COVID-2019 (SARS-CoV-2) pathogenesis with SARS-CoV and MERS-CoV infections. Future Virol 15, 2020.

37. Wang D, Hu B, Hu C, Zhu F, Liu X, Zhang J, Wang B, Xiang H, Cheng Z, Xiong Y, et al: Clinical characteristics of 138 hospitalized patients with 2019 novel coronavirus-infected pneumonia in Wuhan, China. JAMA 323: 1061-1069, 2020

38. Chen T, Wu D, Chen H, Yan W, Yang D, Chen G, Ma K, Xu D, $\mathrm{Yu} \mathrm{H}$, Wang $\mathrm{H}$, et al: Clinical characteristics of 113 deceased patients with coronavirus disease 2019: Retrospective study. BMJ 368: m1091, 2020.

39. Su S, Wong G, Shi W, Liu J, Lai ACK, Zhou J, Liu W, Bi Y and Gao GF: Epidemiology, genetic recombination, and pathogenesis of coronaviruses. Trends Microbiol 24: 490-502, 2016.

40. Wevers BA and van der Hoek L: Recently discovered human coronaviruses. Clin Lab Med 29: 715-724, 2009.

41. Xu X, Chen P, Wang J, Feng J, Zhou H, Li X, Zhong W and Hao P: Evolution of the novel coronavirus from the ongoing Wuhan outbreak and modeling of its spike protein for risk of human transmission. Sci China Life Sci 63: 457-460, 2020.

42. Ren LL, Wang YM, Wu ZQ, Xiang ZC, Guo L, Xu T, Jiang YZ, Xiong Y, Li YJ, Li XW, et al: Identification of a novel coronavirus causing severe pneumonia in human: A descriptive study. Chin Med J (Engl) 133: 1015-1024, 2020.

43. Zhang H, Kang Z, Gong H, Xu D, Wang J, Li Z, Cui X, Xiao J, Meng T, Zhou W, et al: The digestive system is a potential route of 2019-nCov infection: A bioinformatics analysis based on single-cell transcriptomes. bioRxiv, 2020.

44. Zou X, Chen K, Zou J, Han P, Hao J and Han Z: Single-cell RNA-seq data analysis on the receptor ACE2 expression reveals the potential risk of different human organs vulnerable to 2019-nCoV infection. Front Med 14: 185-192, 2020.

45. Huang C, Wang Y, Li X, Ren L, Zhao J, Hu Y, Zhang L, Fan G, Xu J, Gu X, et al: Clinical features of patients infected with 2019 novel coronavirus in Wuhan, China. Lancet 395: 497-506, 2020.

46. Shi H, Han X, Jiang N, Cao Y, Alwalid O, Gu J, Fan Y and Zheng C: Radiological findings from 81 patients with COVID-19 pneumonia in Wuhan, China: A descriptive study. Lancet Infect Dis 20: 425-434, 2020.

47. Li Q, Guan X, Wu P, Wang X, Zhou L, Tong Y, Ren R, Leung KSM, Lau EHY, Wong JY, et al: Early transmission dynamics in Wuhan, China, of novel coronavirus-infected pneumonia. N Engl J Med 382: 1199-1207, 2020.

48. Chen N, Zhou M, Dong X, Qu J, Gong F, Han Y, Qiu Y, Wang J, Liu Y, Wei Y, et al: Epidemiological and clinical characteristics of 99 cases of 2019 novel coronavirus pneumonia in Wuhan, China: A descriptive study. Lancet 395: 507-513, 2020.

49. Loeffelholz MJ and Tang YW: Laboratory diagnosis of emerging human coronavirus infections-the state of the art. Emerg Microbes Infect 9: 747-756, 2020.

50. To KK, Tsang OT, Yip CC, Chan KH, Wu TC, Chan JM, Leung WS, Chik TS, Choi CY, Kandamby DH, et al: Consistent detection of 2019 novel coronavirus in saliva. Clin Infect Dis 71: $841-843,2020$

51. Zhao B, Ni C, Gao R, Wang Y, Yang L, Wei J, Lv T, Liang J, Zhang Q, Xu W, et al: Recapitulation of SARS-CoV-2 infection and cholangiocyte damage with human liver ductal organoids. Protein Cell 11: 771-775, 2020. 
52. Chai X, Hu L, Zhang Y, Han W, Lu Z, Ke A, Zhou J, Shi G, Fang N, Fan J, et al: Specific ACE2 expression in cholangiocytes may cause liver damage after 2019-nCoV infection. bioRxiv, 2020.

53. Leung WK, To KF, Chan PK, Chan HL, Wu AK, Lee N Yuen KY and Sung JJ: Enteric involvement of severe acute respiratory syndrome-associated coronavirus infection. Gastroenterology 125: 1011-1017, 2003.

54. Holshue ML, DeBolt C, Lindquist S, Lofy KH, Wiesman J, Bruce H, Spitters C, Ericson K, Wilkerson S, Tural A, et al: First case of 2019 novel coronavirus in the United States. N Engl J Med 382: 929-936, 2020.

55. Lin W, Hu L, Zhang Y, Ooi JD, Meng T, Jin P, Ding X, Peng L, Song L, Xiao Z, et al: Single-cell analysis of ACE2 expression in human kidneys and bladders reveals a potential route of 2019-nCoV infection. bioRxiv: 2020.02.08.939892, 2020.

56. Fan C, Li K, Ding Y, Lu WL and Wang J: ACE2 expression in kidney and testis may cause kidney and testis damage after 2019-nCoV infection. medRxiv: 2020.02.12.20022418, 2020.

57. Xu Z, Shi L, Wang Y, Zhang J, Huang L, Zhang C, Liu S, Zhao P, Liu H, Zhu L, et al: Pathological findings of COVID-19 associated with acute respiratory distress syndrome. Lancet Respir Med 8: 420-422, 2020.

58. Tian S, Xiong Y, Liu H, Niu L, Guo J, Liao M and Xiao SY: Pathological study of the 2019 novel coronavirus disease (COVID-19) through postmortem core biopsies. Mod Pathol 33: 1007-1014, 2020.

59. Peiris JS, Chu CM, Cheng VC, Chan KS, Hung IF, Poon LL, Law KI Tang BS, Hon TY, Chan CS, et al: Clinical progression and viral load in a community outbreak of coronavirus-associated SARS pneumonia: A prospective study. Lancet 361: 1767-1772, 2003

60. Drosten C, Günther S, Preiser W, van der Werf S, Brodt HR, Becker S, Rabenau H, Panning M, Kolesnikova L, Fouchier RA, et al: Identification of a novel coronavirus in patients with severe acute respiratory syndrome. N Engl J Med 348: 1967-1976, 2003

61. Tang P, Louie M, Richardson SE, Smieja M, Simor AE, Jamieson F, Fearon M, Poutanen SM, Mazzulli T, Tellier R, et al: Interpretation of diagnostic laboratory tests for severe acute respiratory syndrome: The Toronto experience. CMAJ 170 47-54, 2004

62. Pitzer VE, Leung GM and Lipsitch M: Estimating variability in the transmission of severe acute respiratory syndrome to household contacts in Hong Kong, China. Am J Epidemiol 166 : 355-363, 2007.

63. Tang JW, To KF, Lo AW, Sung JJ, Ng HK and Chan PK: Quantitative temporal-spatial distribution of severe acute respiratory syndrome-associated coronavirus (SARS-CoV) in post-mortem tissues. J Med Virol 79: 1245-1253, 2007.

64. Lo YM: SARS diagnosis, monitoring and prognostication by SARS-coronavirus RNA detection. Hong Kong Med J 15 (Suppl 8): S11-S14, 2009.

65. Mahase E: China coronavirus: Mild but infectious cases may make it hard to control outbreak, report warns. BMJ 368:m325, 2020.

66. Zhu N, Wang W, Liu Z, Liang C, Wang W, Ye F, Huang B Zhao L, Wang H, Zhou W, et al: Morphogenesis and cytopathic effect of SARS-CoV-2 infection in human airway epithelial cells Nat Commun 11: 3910, 2020.

67. Kai H and Kai M: Interactions of coronaviruses with ACE2, angiotensin II, and RAS inhibitors-lessons from available evidence and insights into COVID-19. Hypertens Res 43: 648-654, 2020

68. Lee HK, Tso EY, Chau TN, Tsang OT, Choi KW and Lai TS Asymptomatic severe acute respiratory syndrome-associated coronavirus infection. Emerg Infect Dis 9: 1491-1492, 2003.

69. Che XY, Di B, Zhao GP, Wang YD, Qiu LW, Hao W, Wang M, Qin PZ, Liu YF, Chan KH, et al: A patient with asymptomatic severe acute respiratory syndrome (SARS) and antigenemia from the 2003-2004 community outbreak of SARS in Guangzhou, China. Clin Infect Dis 43: e1-e5, 2006.

70. Cowling BJ, Park M, Fang VJ, Wu P, Leung GM and Wu JT: Preliminary epidemiological assessment of MERS-CoV outbreak in South Korea, May to June 2015. Euro Surveill 20: 7-13, 2015.

71. Al-Tawfiq JA: Asymptomatic coronavirus infection: MERS-CoV and SARS-CoV-2 (COVID-19). Travel Med Infect Dis 35 101608, 2020.

72. Wölfel R, Corman VM, Guggemos W, Seilmaier M, Zange S, Müller MA, Niemeyer D, Jones TC, Vollmar P, Rothe C, et al: Virological assessment of hospitalized patients with COVID-2019. Nature 581: 465-469, 2020.
73. Yu X and Yang R: COVID-19 transmission through asymptomatic carriers is a challenge to containment. Influenza Other Respir Viruses 14: 474-475, 2020.

74. Toyoshima Y, Nemoto K, Matsumoto S, Nakamura Y and Kiyotani K: SARS-CoV-2 genomic variations associated with mortality rate of COVID-19. J Hum Genet: 1-8, Jul 22, 2020 (Online ahead of print).

75. Liang W, Guan W, Chen R, Wang W, Li J, Xu K, Li C, Ai Q, $\mathrm{Lu} \mathrm{W}$, Liang H, et al: Cancer patients in SARS-CoV-2 infection: A nationwide analysis in China. Lancet Oncol 21: 335-337, 2020

76. Zhang L, Zhu F, Xie L, Wang C, Wang J, Chen R, Jia P, Guan HQ, Peng L, Chen Y, et al: Clinical characteristics of COVID-19-infected cancer patients: A retrospective case study in three hospitals within Wuhan, China. Ann Oncol 31: 894-901, 2020.

77. Lian J, Jin X, Hao S, Cai H, Zhang S, Zheng L, Jia H, Hu J, Gao J, Zhang Y, et al: Analysis of epidemiological and clinical features in older patients with coronavirus disease 2019 (COVID-19) outside Wuhan. Clin Infect Dis 71: 740-747, 2020.

78. Lei X, Dong X, Ma R, Wang W, Xiao X, Tian Z, Wang C, Wang Y, Li L, Ren L, et al: Activation and evasion of type I interferon responses by SARS-CoV-2. Nat Commun 11: 3810, 2020.

79. Mossel EC, Huang C, Narayanan K, Makino S, Tesh RB and Peters CJ: Exogenous ACE2 expression allows refractory cell lines to support severe acute respiratory syndrome coronavirus replication. J Virol 79: 3846-3850, 2005.

80. Cai G: Tobacco-use disparity in gene expression of ACE2, the receptor of 2019-nCov. medR xiv, 2020.

81. Bergmann CC, Lane T and Stohlman SA: Coronavirus infection of the central nervous system: Host-virus stand-off. Nat Rey Microbiol 4: 121-132, 2006.

82. Takeuchi $\mathrm{O}$ and Akira S: Innate immunity to virus infection. Immunol Rev 227: 75-86, 2009.

83. Fung TS and Liu DX: Human coronavirus: Host-pathogen interaction. Annu Rev Microbiol 73: 529-557, 2019.

84. Perlman S and Dandekar AA: Immunopathogenesis of coronavirus infections: Implications for SARS. Nat Rev Immunol 5: 917-927, 2005.

85. Newton AH, Cardani A and Braciale TJ: The host immune response in respiratory virus infection: Balancing virus clearance and immunopathology. Semin Immunopathol 38: 471-482, 2016.

86. Li SW, Wang CY, Jou YJ, Huang SH, Hsiao LH, Wan L, Lin YJ, Kung SH and Lin CW: SARS coronavirus papain-like protease inhibits the TLR7 signaling pathway through removing Lys63-linked polyubiquitination of TRAF3 and TRAF6. Int J Mol Sci 17: 678, 2016.

87. Cervantes-Barragan L, Lewis K, Firner S, Thiel V, Hugues S, Reith W, Ludewig B and Reizis B: Plasmacytoid dendritic cells control T-cell response to chronic viral infection. Proc Natl Acad Sci USA 109: 3012-3017, 2012.

88. Li H, Wang YM, Xu JY and Cao B: Potential antiviral therapeutics for 2019 novel coronavirus. Zhonghua Jie $\mathrm{He} \mathrm{He} \mathrm{Hu} \mathrm{Xi} \mathrm{Za}$ Zhi 43: E002, Jul 23, 2020 (Epub ahead of print) (In Chinese).

89. Versteeg GA, Bredenbeek PJ, van den Worm SH and Spaan WJ: Group 2 coronaviruses prevent immediate early interferon induction by protection of viral RNA from host cell recognition. Virology 361: 18-26, 2007.

90. Lui PY, Wong LY, Fung CL, Siu KL, Yeung ML, Yuen KS, Chan CP, Woo PC, Yuen KY and Jin DY: Middle East respiratory syndrome coronavirus $\mathrm{M}$ protein suppresses type $\mathrm{I}$ interferon expression through the inhibition of TBK1-dependent phosphorylation of IRF3. Emerg Microbes Infect 5: e39, 2016.

91. Siu KL, Chan CP, Kok KH, Chiu-Yat Woo P and Jin DY: Suppression of innate antiviral response by severe acute respiratory syndrome coronavirus $\mathrm{M}$ protein is mediated through the first transmembrane domain. Cell Mol Immunol 11: 141-149, 2014.

92. Cheung CY, Poon LL, Ng IH, Luk W, Sia SF, Wu MH, Chan KH, Yuen KY, Gordon S, Guan Y and Peiris JS: Cytokine responses in severe acute respiratory syndrome coronavirus-infected macrophages in vitro: Possible relevance to pathogenesis. J Virol 79: 7819-7826, 2005.

93. Law HK, Cheung CY, Ng HY, Sia SF, Chan YO, Luk W, Nicholls JM, Peiris JS and Lau YL: Chemokine up-regulation in SARS-coronavirus-infected, monocyte-derived human dendritic cells. Blood 106: 2366-2374, 2005

94. Wong CK, Lam C, Wu AK, Ip WK, Lee NL, Chan IH, Lit LC, Hui DS, Chan MH, Chung SS and Sung JJ: Plasma inflammatory cytokines and chemokines in severe acute respiratory syndrome. Clin Exp Immunol 136: 95-103, 2004. 
95. Zhang Y,Li J, Zhan Y, Wu L, Yu X, Zhang W, Ye L, Xu S, Sun R, Wang Y and Lou J: Analysis of serum cytokines in patients with severe acute respiratory syndrome. Infect Immun 72: 4410-4415, 2004

96. Tynell J, Westenius V, Rönkkö E, Munster VJ, Melén K, Österlund P and Julkunen I: Middle East respiratory syndrome coronavirus shows poor replication but significant induction of antiviral responses in human monocyte-derived macrophages and dendritic cells. J Gen Virol 97: 344-355, 2016.

97. Zhou J, Chu H, Li C, Wong BH, Cheng ZS, Poon VK, Sun T, Lau CC, Wong KK, Chan JY, et al: Active replication of Middle East respiratory syndrome coronavirus and aberrant induction of inflammatory cytokines and chemokines in human macrophages: Implications for pathogenesis. J Infect Dis 209: 1331-1342, 2014.

98. Lau SKP, Lau CCY, Chan KH, Li CPY, Chen H, Jin DY, Chan JFW, Woo PCY and Yuen KY: Delayed induction of proinflammatory cytokines and suppression of innate antiviral response by the novel Middle East respiratory syndrome coronavirus: Implications for pathogenesis and treatment. J Gen Virol 94: 2679-2690, 2013.

99. Kim ES, Choe PG, Park WB, Oh HS, Kim EJ, Nam EY, Na SH, Kim M, Song KH, Bang JH, et al: Clinical progression and cytokine profiles of Middle East respiratory syndrome coronavirus infection. J Korean Med Sci 31: 1717-1725, 2016.

100. Min CK, Cheon S, Ha NY, Sohn KM, Kim Y, Aigerim A, Shin HM, Choi JY, Inn KS, Kim JH, et al: Comparative and kinetic analysis of viral shedding and immunological responses in MERS patients representing a broad spectrum of disease severity. Sci Rep 6: 25359, 2016

101. Wong RS, Wu A, To KF, Lee N, Lam CW, Wong CK, Chan PK, $\mathrm{Ng} \mathrm{MH,} \mathrm{Yu} \mathrm{LM,} \mathrm{Hui} \mathrm{DS,} \mathrm{et} \mathrm{al:} \mathrm{Haematological} \mathrm{manifestations} \mathrm{in}$ patients with severe acute respiratory syndrome: Retrospective analysis. BMJ 326: 1358-1362, 2003

102. Li T, Qiu Z, Zhang L, Han Y, He W, Liu Z, Ma X, Fan H, Lu W, Xie J, et al: Significant changes of peripheral T lymphocyte subsets in patients with severe acute respiratory syndrome. J Infect Dis 189: 648-651, 2004.

103. Cui W, Fan Y, Wu W, Zhang F, Wang JY and Ni AP: Expression of lymphocytes and lymphocyte subsets in patients with severe acute respiratory syndrome. Clin Infect Dis 37: 857-859, 2003.

104. Assiri A, Al-Tawfiq JA, Al-Rabeeah AA, Al-Rabiah FA, Al-Hajjar S, Al-Barrak A, Flemban H, Al-Nassir WN, Balkhy HH, Al-Hakeem RF, et al: Epidemiological, demographic, and clinical characteristics of 47 cases of Middle East respiratory syndrome coronavirus disease from Saudi Arabia: A descriptive study. Lancet Infect Dis 13: 752-761, 2013.

105. Usul E, Şan İ, Bekgöz B and Şahin A: The role of hematological parameters in COVID-19 patients in the emergency room. Biomark Med 14: 1207-1215, 2020

106. Cai C, Zeng X, Ou AH, Huang Y and Zhang X: Study on T cell subsets and their activated molecules from the convalescent SARS patients during two follow-up surveys. Xi Bao Yu Fen Zi Mian Yi Xue Za Zhi 20: 322-324, 2004 (In Chinese)

107. Yu XY, Zhang YC, Han CW, Wang P, Xue XJ and Cong YL: Change of T lymphocyte and its activated subsets in SARS patients. Zhongguo Yi Xue Ke Xue Yuan Xue Bao 25: 542-546, 2003 (In Chinese).

108. van den Brand JM, Haagmans BL, van Riel D, Osterhaus AD and Kuiken T: The pathology and pathogenesis of experimental severe acute respiratory syndrome and influenza in animal models. J Comp Pathol 151: 83-112, 2014.

109. Gretebeck LM and Subbarao K: Animal models for SARS and MERS coronaviruses. Curr Opin Virol 13: 123-129, 2015.

110. Roberts A, Paddock C, Vogel L, Butler E, Zaki S and Subbarao K Aged BALB/c mice as a model for increased severity of severe acute respiratory syndrome in elderly humans. J Virol 79 $5833-5838,2005$

111. Zhao J, Zhao J, Legge K and Perlman S: Age-related increases in PGD(2) expression impair respiratory DC migration, resulting in diminished $\mathrm{T}$ cell responses upon respiratory virus infection in mice. J Clin Invest 121: 4921-4930, 2011.

112. Li T, Qiu Z, Han Y, Wang Z, Fan H, Lu W, Xie J, Ma X and Wang A: Rapid loss of both CD4+ and CD8+ T lymphocyte subsets during the acute phase of severe acute respiratory syndrome. Chin Med J (Engl) 116: 985-987, 2003.

113. Kim KD, Zhao J, Auh S, Yang X, Du P, Tang H and Fu YX: Adaptive immune cells temper initial innate responses. Nat Med 13: 1248-1252, 2007.
114. Yang L, Peng H, Zhu Z, Li G, Huang Z, Zhao Z, Koup RA, Bailer RT and Wu C: Persistent memory CD4+ and CD8+ $\mathrm{T}$-cell responses in recovered severe acute respiratory syndrome (SARS) patients to SARS coronavirus M antigen. J Gen Virol 88: 2740-2748, 2007.

115. Yang LT, Peng H, Zhu ZL, Li G, Huang ZT, Zhao ZX, Koup RA, Bailer RT and Wu CY: Long-lived effector/central memory T-cell responses to severe acute respiratory syndrome coronavirus (SARS-CoV) S antigen in recovered SARS patients. Clin Immunol 120: 171-178, 2006.

116. Peng H, Yang LT, Wang LY, Li J, Huang J, Lu ZQ, Koup RA, Bailer RT and Wu CY: Long-lived memory T lymphocyte responses against SARS coronavirus nucleocapsid protein in SARS-recovered patients. Virology 351: 466-475, 2006.

117. Chen H, Hou J, Jiang X, Ma S, Meng M, Wang B, Zhang M, Zhang M, Tang X, Zhang F, et al: Response of memory $\mathrm{CD} 8+\mathrm{T}$ cells to severe acute respiratory syndrome (SARS) coronavirus in recovered SARS patients and healthy individuals. J Immunol 175: 591-598, 2005

118. Rodriguez-Morales AJ, Cardona-Ospina JA, Gutiérrez-Ocampo E, Villamizar-Peña R, Holguin-Rivera Y, Escalera-Antezana JP, Alvarado-Arnez LE, Bonilla-Aldana DK, Franco-Paredes C, Henao-Martinez AF, et al: Clinical, laboratory and imaging features of COVID-19: A systematic review and meta-analysis. Travel Med Infect Dis 34: 101623, 2020.

119. Zu ZY, Jiang MD, Xu PP, Chen W, Ni QQ, Lu GM and Zhang LJ: Coronavirus disease 2019 (COVID-19): A perspective from China. Radiology 296: E15-E25, 2020.

120. Liu H, Liu F, Li J, Zhang T, Wang D and Lan W: Clinical and CT imaging features of the COVID-19 pneumonia: Focus on pregnant women and children. J Infect 80: e7-e13, 2020.

121. Umar A, Boisseau M, Segur MC, Begaud B and Moore N: Effect of age of Armagnac extract and duration of treatment on antithrombotic effects in a rat thrombosis model. Thromb Res 111: $185-189,2003$

122. Gu J, Gong E, Zhang B, Zheng J, Gao Z, Zhong Y, Zou W, Zhan J, Wang S, Xie Z, et al: Multiple organ infection and the pathogenesis of SARS. J Exp Med 202: 415-424, 2005.

123. Nicholls JM, Poon LL, Lee KC, Ng WF, Lai ST, Leung CY, Chu CM, Hui PK, Mak KL, Lim W, et al: Lung pathology of fatal severe acute respiratory syndrome. Lancet 361: 1773-1778, 2003.

124. Ng DL, Al Hosani F, Keating MK, Gerber SI, Jones TL, Metcalfe MG, Tong S, Tao Y, Alami NN, Haynes LM, et al: Clinicopathologic, immunohistochemical, and ultrastructural findings of a fatal case of middle east respiratory syndrome coronavirus infection in the United Arab Emirates, April 2014 Am J Pathol 186: 652-658, 2016.

125. Bhatia M and Moochhala S: Role of inflammatory mediators in the pathophysiology of acute respiratory distress syndrome. J Pathol 202: 145-156, 2004.

126. Lew TW, Kwek TK, Tai D, Earnest A, Loo S, Singh K, Kwan KM, Chan Y, Yim CF, Bek SL, et al: Acute respiratory distress syndrome in critically ill patients with severe acute respiratory syndrome. JAMA 290: 374-380, 2003.

127. Jiang Y, Xu J, Zhou C, Wu Z, Zhong S, Liu J, Luo W, Chen T, Qin Q and Deng P: Characterization of cytokine/chemokine profiles of severe acute respiratory syndrome. Am J Respir Crit Care Med 171: 850-857, 2005

128. Wuhan Municipal Health Commission. Report of clustering pneumonia of unknown etiology in Wuhan City. Wuhan, China, 2019. http://wjw.wuhan.gov.cn/front/web/showDetail/2019123108989.

129. Vabret N, Britton GJ, Gruber C, Hegde S, Kim J, Kuksin M, Levantovsky R, Malle L, Moreira A,Park MD, et al: Immunology of COVID-19: Current state of the science. Immunity 52: 910-941, 2020

130. Zhang D, Guo R, Lei L, Liu H, Wang Y, Wang Y, Dai T, Zhang T, Lai Y, Wang J, et al: COVID-19 infection induces readily detectable morphological and inflammation-related phenotypic changes in peripheral blood monocytes, the severity of which correlate with patient outcome. medRxiv: 2020.03.24.20042655, 2020.

131. Cameron MJ, Bermejo-Martin JF, Danesh A, Muller MP and Kelvin DJ: Human immunopathogenesis of severe acute respiratory syndrome (SARS). Virus Res 133: 13-19, 2008.

132. Ye Q, Wang B and Mao J: The pathogenesis and treatment of the 'Cytokine Storm' in COVID-19. J Infect 80: 607-613, 2020.

133. Channappanavar R and Perlman S: Pathogenic human coronavirus infections: Causes and consequences of cytokine storm and immunopathology. Semin Immunopathol 39: 529-539, 2017 
134. Xiang-Hua Y, Le-Min W, Ai-Bin L, Zhu G, Riquan L, Xu-You Z, Wei-Wei R and Ye-Nan W: Severe acute respiratory syndrome and venous thromboembolism in multiple organs. Am J Respir Crit Care Med 182: 436-437, 2010.

135. Iba TA-O and Levy JH: Inflammation and thrombosis: Roles of neutrophils, platelets and endothelial cells and their interactions in thrombus formation during sepsis. J Thromb Haemost 16 : 231-241, 2018

136. Akira S, Uematsu S and Takeuchi O: Pathogen recognition and innate immunity. Cell 124: 783-801, 2006.

137. Connors JM and Levy JH: COVID-19 and its implications for thrombosis and anticoagulation. Blood 135: 2033-2040, 2020.

138. JacksonS,DarboussetRandSchoenwaelderS:Thromboinflammation: Challenges of therapeutically targeting coagulation and other host defense mechanisms. Blood 133: 906-918, 2019.

139. Iba T, Levy JH, Wada H, Thachil J, Warkentin T and Levi M; Subcommittee on Disseminated Intravascular Coagulation: Differential diagnoses for sepsis-induced disseminated intravascular coagulation: Communication from the SSC of the ISTH. J Thromb Haemost 17: 415-419, 2019.
140. Goshua G, Pine AB, Meizlish ML, Chang CH, Zhang H, Bahel P, Baluha A, Bar N, Bona RD, Burns AJ, et al: Endotheliopathy in COVID-19-associated coagulopathy: Evidence from a single-centre, cross-sectional study. Lancet Haematol 7: e575-e582, 2020.

141. Del Turco S, Vianello A, Ragusa R, Caselli C and Basta G: COVID-19 and cardiovascular consequences: Is the endothelial dysfunction the hardest challenge? Thromb Res 196: 143-151, Aug 24, 2020 (Epub ahead of print).

This work is licensed under a Creative Commons Attribution-NonCommercial-NoDerivatives 4.0 International (CC BY-NC-ND 4.0) License. 